\title{
BMJ Open Validation study: evaluation of the metrological quality of French hospital data for perinatal algorithms
}

\author{
Karine Goueslard, ${ }^{1,2,3,4}$ Jonathan Cottenet, ${ }^{1,2,3,4}$ Eric Benzenine, , ,2,3,4 \\ Pascale Tubert-Bitter, ${ }^{5}$ Catherine Quantin (i) ${ }^{6}$
}

To cite: Goueslard K, Cottenet J, Benzenine $\mathrm{E}$, et al. Validation study: evaluation of the metrological quality of French hospital data for perinatal algorithms. BMJ Open 2020;10:e035218. doi:10.1136/ bmjopen-2019-035218

- Prepublication history and additional material for this paper are available online. To view these files, please visit the journal online (http://dx.doi. org/10.1136/bmjopen-2019035218).

Received 24 0ctober 2019 Revised 28 February 2020 Accepted 14 April 2020

Check for updates

(c) Author(s) (or their employer(s)) 2020. Re-use permitted under CC BY-NC. No commercial re-use. See rights and permissions. Published by BMJ.

${ }^{1}$ Biostatistics and Bioinformatics (DIM), Inserm, CIC 1432, Dijon,

France

${ }^{2}$ University Hospital, Dijon,

France

${ }^{3}$ Bourgogne Franche-Comté University, Dijon, France

${ }^{4}$ Centre Hospitalier Universitaire de Dijon, Dijon, Bourgogne, France

${ }^{5}$ Biostatistics, Biomathematics, Pharmacoepidemiology and Infectious Diseases (B2PHI), Inserm, UVSQ, Institut Pasteur, Université Paris-Saclay, INSERM, Villejuif, Île-de-France, France

${ }^{6}$ Service de Biostatistique et Informatique Médicale, Centre Hospitalier Universitaire, Dijon, France

Correspondence to

Dr Catherine Quantin;

catherine.quantin@chu-dijon.fr

\section{ABSTRACT}

Objective The aim of our validation study was to assess the metrological quality of hospital data for perinatal algorithms on a national level.

Design Validation study.

Setting This was a multicentre study of the French medicoadministrative database on perinatal indicators. Participants In each hospital, we selected 150 discharge abstracts for delivery (after 22 weeks of gestation), in 2014, and their corresponding medical records. Overall, 22 hospitals were included.

Interventions A single investigator performed blind data collection from medical records in order to compare data from discharge abstracts with data from medical records. Finally, 3246 discharge abstracts were studied. Primary and secondary outcome measures Seventy items, including maternal and delivery characteristics and maternal morbidity, were collected for each delivery stay. Results The concordance rate of maternal age at delivery was $94.8 \%$ (95\% Cl 93.8 to 95.4). Combining the two forms of pre-existing diabetes, the algorithm presented a PPV of $65.9 \%$ and a sensitivity of $75.7 \%$. The concordance rate of gestational age at delivery was $91.8 \%$ (90.9 to 92.7). Regarding gestational diabetes, the PPV was $80.8 \%$ (79.4 to 82.2 ) and the sensitivity was $79.5 \%$ (78.1 to 80.9 ). Regardless of the algorithm explored, the PPV for vaginal delivery was over $99 \%$. For the diagnosis codes corresponding to immediate postpartum haemorrhage, the PPV was $77.7 \%$ (76.3 to $79.1)$ and the sensitivity was $75.5 \%$ (74.0 to 77.0$)$. The algorithm for stillbirth presented a PPV of $89.4 \%$ (88.3 to $90.5)$ and a sensitivity of $95.4 \%$ (94.7 to 96.1$)$.

Conclusions This first national validation study of many perinatal algorithms suggests that the French national hospital database is an appropriate data source for epidemiological studies, except for some indicators which presented low PPV and/or sensitivity.

\section{INTRODUCTION}

Subsequent to the digitisation of hospital data, a great deal of epidemiological data about the hospitalised population have become available; these have been used de facto for scientific research for more than 20 years. $^{1-6}$ In this context, health data have focused on identifying morbidity using diagnosis and/or procedure data that

\section{Strengths and limitations of this study}

The study was conducted on individual data, which made it possible to assess positive predictive value and sensitivity.

- The study included all types of maternity units and all volumes of deliveries.

- The data collection was performed by a single technician.

- There was heterogeneous distribution of maternity units throughout the French territory.

- Data collection was not duplicated by a health professional, and there was no dual data collection by a health professional.

may reflect the health status of individual subjects. In France, the medical information system (Programme de Médicalisation des Systèmes d'Information) covers data relative to all public and private hospitals throughout the territory. These data are particularly interesting for the investigation of perinatal health, seeing as $99.6 \%$ of the 800000 annual births in France take place in hospitals. ${ }^{7}$ Even though national perinatal surveys are currently used to follow up on numerous indicators every 5 years, hospital database is also a suitable epidemiological tool because it makes information available on a yearly basis. ${ }^{8} 9$ The use of routinely collected health data saves time and money when identifying infrequent and unfavourable delivery outcomes and improves health surveillance of women and their offspring. ${ }^{10}$

Because hospital data were originally collected for administrative or financial purposes, the researchers using these databases are required to ensure data quality using either a single variable or a casefinding algorithm based on several variables. ${ }^{10-14}$ It then becomes an evaluation of data reliability: a declared case has to be a confirmed case. A validation study aims to evaluate the gap between the information 
found in the medicoadministrative database and the information found with a gold standard approach. This type of study performed from individual data is extremely time-consuming and expensive because the data from medical records require prior national data collection. Nonetheless, this type of validation study needs to be carried out for each database seeing as variations can occur. ${ }^{15}$ For instance, a Canadian study validated an identification algorithm for children with diabetes mellitus, but the identification of children with diabetes using the same algorithm was insufficient in a Colombian database. ${ }^{16} 17$ The relevant question here is whether the French hospital database can be used to reliably detect perinatal indicators and therefore to inform clinical studies or investigate quality of care.

The aim of our validation study was to assess the metrological quality of hospital data for perinatal algorithms on a national level.

\section{METHODS}

The principle of this transversal multicentre study was to compare data from the French hospital database (named 'Programme de Médicalisation des Systèmes d'Information' or PMSI) with data from medical records, which we considered to be the gold standard. The objective of a validation study for a case-finding algorithm is to estimate the validity indices of the algorithm which quantifies to what extent a variable in the data corresponds to the variable in reality.

\section{French hospital database}

The French hospital database, which uses diagnosisrelated groups (DRG), is a patient classification system with an objective to describe hospital activity according to the resources consumed. In France, the classification of DRG is based on discharge abstracts recorded for each hospitalisation. These abstracts include some sociodemographic characteristics, the principal and associated diagnoses (coded according to the 10th revision of the International Statistical Classification of Diseases and Related Health Problems), and procedures performed during the stay (coded according to the French Common Classification of Medical Acts) for each inpatient. Several internal and external controls are periodically performed. Although the purpose of this database is the payment of clinical hospital activities, this database has already been the subject of numerous studies in various medical disciplines, notably in a perinatal setting. ${ }^{718-23}$

\section{Population}

We performed a two-stage sample design. First, 50 health hospitals with a maternity unit were randomly selected in metropolitan France (other than Paris and Paris region), irrespective of the level of the unit. In France, maternity units are classified into levels according to the care they are able to provide (online supplementary file 1). Two hospitals that had participated in a previous pilot study were automatically included. The heads of the maternity units were contacted by an email where we presented the study and asked if the unit would be interested in taking part. We followed up by telephone hospitals that did not answer.

Second, for each included hospital, 150 delivery discharge abstracts ( $\geq 22$ weeks of gestation) were randomly selected from all the discharge abstracts from 2014 that contained a Z37 code (the outcome of delivery on the mother's record) and/or a delivery procedure, according to the French Common Classification. We chose to include 150 records per hospital to reach the minimum sample size required, ${ }^{24}$ based on the different values of the prevalence of a disease and both the sensitivity and specificity of a screening procedure or diagnostic test. Except for one simulation out of 40, we reached the minimum sample size required for the diagnostic tests.

Particular interest was paid to diabetes mellitus, severe postpartum haemorrhage ( $\mathrm{PPH})$, stillbirth and termination of pregnancy for medical reasons. These conditions are relatively rare and could be under-represented in a simple random sample selection. We therefore used the quota method.

The selected discharge abstracts were distributed as follows:

- 80 discharge abstracts selected from all deliveries, whatever the pregnancy outcome.

- 10 discharge abstracts selected from all deliveries, including a diagnosis code for pre-existing type 2 or type 1 diabetes mellitus, in pregnancy, childbirth and the puerperium.

- 10 discharge abstracts selected from all deliveries, including a diagnosis code for gestational diabetes mellitus (GDM).

- 20 discharge abstracts selected from all deliveries, including a diagnosis code for severe PPH.

- 20 discharge abstracts selected from all deliveries, including a diagnosis code for stillbirth.

- 10 discharge abstracts selected from all deliveries, including a diagnosis code for a termination of pregnancy for medical reasons.

For the last two groups, all discharge abstracts were included if the number of cases was not reached in 2014 for a given hospital. To maintain the number of 150 for this hospital, an additional random draw was performed among discharge abstracts selected from all deliveries.

We developed a software program to randomly select 150 discharge abstracts that included a delivery per hospital. Each hospital's medical information department ran this program in its hospital database to extract the data for these 150 stays for delivery and the 150 corresponding medical records.

A list of 25 additional discharge abstracts (12 all deliveries, 3 diabetes mellitus, 3 GDM, 3 severe PPH, 2 stillbirths and 2 terminated pregnancy for medical reasons) was prepared to compensate for inaccessible records if 
necessary, thus maintaining the number of 150 discharge abstracts per hospital.

\section{Data collection}

A single clinical research associate collected data in each hospital from the hospital perinatal medical records of women who delivered in 2014. These medical records were linked to the previously selected discharge abstracts. The clinical research associate was trained to collect and manage data and was blinded to the data recorded on the discharge abstracts. Data collection took place between September 2016 and December 2017.

The medical record was made up of an electronic or paper document that retraced prenatal care, the delivery and the postdelivery stay, a report of the procedure, and a discharge letter. The data from each record were collected on a standardised form in accordance with national predefined guidelines regarding the collection of hospital data. Guidelines for filling in information and the opportunity to discuss the disputed cases with a supervisor with expertise in obstetrics allowed us to maximise data homogeneity.

The variables studied corresponded to the characteristics of the hospital stay, the pregnancy, the delivery and the newborn: the mode of admission and discharge, the length of stay, the maternal age at delivery, the existence of maternal obesity (body mass index (BMI) $>30 \mathrm{~kg} / \mathrm{m}^{2}$ ), the weight and gestational age of the newborn, and the parity for vaginal deliveries (accounted after delivery). Maternal diseases included diabetes before the pregnancy, gestational diabetes, hypertensive disorders, premature rupture of membranes (PROM) and premature labour. The characteristics of the labour and delivery included the type of pregnancy (singleton or multiple), the type of presentation, the mode of delivery (spontaneous vaginal, instrumental extraction, caesarean: emergency or not), and $\mathrm{PPH}$, stillbirth and transfer in utero.

\section{Statistical analysis}

We compared the data from medical records and the data from discharge abstracts, at an individual level. Several algorithms were explored, including different combinations of codes in the discharge abstracts from delivery stays, pregnancy stays or hospitalisation in the 2 years before delivery (online supplementary file 2).

Means or proportions were calculated for each source of data. To evaluate the metrological quality of the hospital database, the various indicators were calculated for each variable. The medical record was considered the gold standard. Positive predictive value (PPV) and sensitivity were calculated for dichotomous data. PPV corresponded to the probability that the variables recorded in the discharge abstracts were also present in the medical record. Sensitivity corresponded to the probability that variables recorded in the medical record were also present in the discharge abstracts.

Continuous data were assessed by the concordance rate, which corresponded to the number of concordant cases between the discharge abstracts and the medical records (ie, if the same value was identified in both data sources) over the total number of records examined. However, the variability of a quantitative measure has two main sources: the method itself (analytical variability) and the individual (intersubject or intrasubject variability). We used the Deming regression ${ }^{25-27}$ to take these variabilities into account. If the two measures are estimated on the same scale, then the methods are well calibrated when the $95 \%$ CI for the intercept includes 0 and the CI for the slope includes 1 . Concerning qualitative variables, in order to estimate the concordance between data of discharge abstracts and medical records, we calculated the kappa index,${ }^{28}$ and the interpretation was made using a commonly cited scale. ${ }^{29}$ This index is considered as good from $60 \%$ (substantial agreement) and excellent from $80 \%$ (almost perfect agreement). The rates of false negative and false positive were also calculated in order to select the best algorithms with regard to the likelihood ratio (balancing specificity and sensitivity).

\section{Patient and public involvement}

No patients involved.

\section{RESULTS}

Twenty-three hospitals agreed to take part in the study (authorised by the head obstetrician and the hospital director): four level 1 maternities, seven level 2 maternities and twelve level 3 maternities.

The distribution of the hospitals was unequal over the territory, but the four major geographical areas were represented.

One hospital did not provide the data from discharge abstracts obtained from the random draw, so only 22 hospitals were finally included.

Fifty-four discharge abstracts could not be linked with the corresponding medical records. For three of them, the data collection was missing in the medical records. Fifty-one discharge abstracts could not be matched with the medical records because a mistake was made in the joint patient identifier for both data sources by the corresponding hospital.

In total, 3246 discharge abstracts were compared with their corresponding medical records.

\section{Maternal indicators}

The concordance rate of maternal age at delivery was 94.8\% (95\% CI 94.0 to 95.6). The concordance rate for postal codes was $97.0 \%$ (96.4 to 97.6) and the concordance rate for departments was $100 \%$. The concordance using Deming regression between data from discharge abstracts and data from medical records is presented in figure 1 . The data include maternal age at delivery, gestational age, childbirth weight and maternal departments of residence. For all these variables the concordance was almost perfect as the $95 \%$ CI for the intercept includes 0 and the CI for the slope includes 1. 

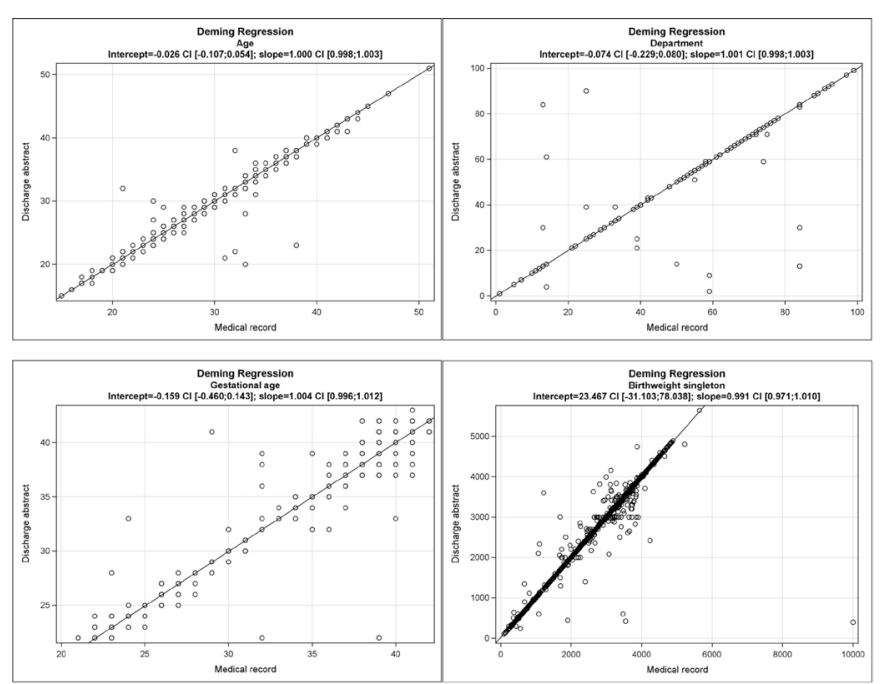

Figure 1 Concordance using Deming regression between discharge abstracts and medical records for maternal age at delivery, gestational age, childbirth weight and maternal departments of residence.

The maternal characteristics are presented in table 1 . The maternal weight and/or height were not available in 309 medical records, making it impossible to calculate BMI. The diagnosis code for obesity $\left(\geq 30 \mathrm{~kg} / \mathrm{m}^{2}\right.$; E66 codes, except E66.03, E66.13, E66.83 and E66.93) presented a PPV of $91.7 \%$ (95\% CI 90.7 to 92.7 ) and a sensitivity of $39.1 \%$ (37.3 to 40.9) (kappa index=0.50, moderate agreement).

We explored parity, which was taken into account after vaginal delivery: the PPV and sensitivity of primiparous women were, respectively, $93.3 \%$ (92.3 to 94.3$)$ and 92.4\% (91.3 to 93.5). For multiparous women, the PPV and sensitivity were of the same order $95.5 \%$ (94.7 to 96.3). The kappa index for parity was greater than 0.80 (almost perfect agreement).

Regarding uterine scars, the PPV was $94.8 \%$ (94.0 to 95.6) and the sensitivity was $78.5 \%$ (77.1 to 79.9) (kappa index $=0.84$, almost perfect agreement .

Maternal morbidity

Several types of morbidity were explored (table 1).

\section{Diabetes mellitus}

First, we focused on pre-existing diabetes mellitus. For type 1 diabetes, the two best algorithms presented a PPV of $50.4 \%$ ( 48.7 to 52.1 ) and a sensitivity of $73.5 \%$ ( 72.0 to 75.0) (kappa index $=0.58$, moderate agreement) and were defined as follows:

- Code O24.0 recorded in discharge abstracts established for delivery stay.

- Code O24.0 recorded in discharge abstracts established for delivery stay and/or code of type 1 diabetes mellitus (E10) recorded in discharge abstracts for hospital stay during pregnancy.

For type 2 diabetes, the best algorithm only included the O24.1 code recorded during pregnancy stay or delivery stay, and it presented a PPV of $67.7 \%$ (66.1 to 69.3) and a sensitivity of $41.2 \%$ (39.5 to 42.9 ) (kappa index=0.51, moderate agreement).

We explored other algorithms which included the E10 code (or E11 for type 2 diabetes) recorded on pregnancy

Table 1 Metrological quality of discharge abstracts for maternal characteristics and comorbidities

\begin{tabular}{|c|c|c|c|c|c|c|c|c|c|c|c|c|c|}
\hline & \multicolumn{2}{|c|}{$\begin{array}{l}\text { Medical } \\
\text { records }\end{array}$} & \multicolumn{2}{|c|}{$\begin{array}{l}\text { Discharge } \\
\text { abstracts }\end{array}$} & \multicolumn{2}{|l|}{ PPV } & \multicolumn{2}{|l|}{ FP } & \multicolumn{2}{|l|}{ FN } & \multicolumn{2}{|c|}{ Sensitivity } & \multirow[t]{2}{*}{$\begin{array}{l}\text { Kappa } \\
\text { index }\end{array}$} \\
\hline & $\mathbf{n}$ & $\%$ & $\mathbf{n}$ & $\%$ & $\%$ & $95 \% \mathrm{Cl}$ & $\mathbf{n}$ & $\%$ & $\mathbf{n}$ & $\%$ & $\%$ & $95 \% \mathrm{Cl}$ & \\
\hline \multicolumn{14}{|l|}{ Parity } \\
\hline $\begin{array}{l}\text { Primiparous } \\
\text { women }\end{array}$ & 981 & 40.2 & 971 & 39.8 & 93.3 & 92.3 to 94.3 & 65 & 2.7 & 75 & 3.1 & 92.4 & 91.3 to 93.5 & 0.88 (APA) \\
\hline $\begin{array}{l}\text { Multiparous } \\
\text { women }\end{array}$ & 1459 & 59.8 & 1458 & 59.8 & 95.5 & 94.7 to 96.3 & 66 & 2.7 & 67 & 2.7 & 95.5 & 94.7 to 96.3 & 0.89 (APA) \\
\hline $\begin{array}{l}\text { Overweight or } \\
\text { obesity } \geq 25 \mathrm{~kg} / \mathrm{m}^{2 *}\end{array}$ & 1104 & 37.6 & 220 & 7.5 & 98.6 & 98.2 to 99.0 & 3 & 0.1 & 887 & 30.2 & 19.7 & 18.3 to 21.1 & $0.23(\mathrm{FA})$ \\
\hline Obesity $\geq 30 \mathrm{~kg} / \mathrm{m}^{2 *}$ & 507 & 17.3 & 216 & 7.4 & 91.7 & 90.7 to 92.7 & 18 & 0.6 & 309 & 10.5 & 39.1 & 37.3 to 40.9 & 0.50 (MA) \\
\hline Uterus scar & 464 & 14.4 & 384 & 11.9 & 94.8 & 94.0 to 95.6 & 20 & 0.6 & 100 & 3.1 & 78.5 & 71.1 to 79.9 & 0.84 (APA) \\
\hline \multicolumn{14}{|l|}{ Diabetes mellitus } \\
\hline Type 1 diabetes $†$ & 98 & 3.0 & 143 & 4.4 & 50.4 & 48.7 to 52.1 & 71 & 2.2 & 26 & 0.8 & 73.5 & 72.0 to 75.0 & $0.58(\mathrm{MA})$ \\
\hline Type 2 diabetes $†$ & 51 & 1.6 & 31 & 1.0 & 67.7 & 66.1 to 69.3 & 10 & 0.3 & 30 & 0.9 & 41.2 & 39.5 to 42.9 & 0.51 (MA) \\
\hline $\begin{array}{l}\text { Type } 1 \text { or type } 2 \\
\text { diabetes }\end{array}$ & 148 & 4.6 & 170 & 5.2 & 65.9 & 64.3 to 67.5 & 58 & 1.8 & 36 & 1.1 & 75.7 & 74.2 to 77.2 & $0.69(\mathrm{SA})$ \\
\hline High blood pressure & 29 & 0.9 & 34 & 1.0 & 32.4 & 30.8 to 34.0 & 23 & 0.7 & 18 & 0.6 & 37.9 & 36.2 to 39.6 & 0.34 (FA) \\
\hline
\end{tabular}


Table 2 Metrological quality of discharge abstracts for pregnancy-related disorders

\begin{tabular}{|c|c|c|c|c|c|c|c|c|c|c|c|c|c|}
\hline & \multicolumn{2}{|c|}{$\begin{array}{l}\text { Medical } \\
\text { records }\end{array}$} & \multicolumn{2}{|c|}{$\begin{array}{l}\text { Discharge } \\
\text { abstracts }\end{array}$} & \multicolumn{2}{|l|}{ PPV } & \multicolumn{2}{|l|}{ FP } & \multicolumn{2}{|l|}{ FN } & \multicolumn{2}{|c|}{ Sensitivity } & \multirow[t]{2}{*}{$\begin{array}{l}\text { Kappa } \\
\text { index }\end{array}$} \\
\hline & $\mathbf{n}$ & $\%$ & $\mathbf{n}$ & $\%$ & $\%$ & $95 \% \mathrm{Cl}$ & $\mathbf{n}$ & $\%$ & $\mathbf{n}$ & $\%$ & $\%$ & $95 \% \mathrm{Cl}$ & \\
\hline Code O24.4 & 482 & 14.9 & 469 & 14.5 & 80.6 & 79.2 to 82.0 & 91 & 2.8 & 104 & 3.2 & 78.4 & 77.0 to 79.8 & $0.76(\mathrm{SA})$ \\
\hline Codes O24.4-O24.9 & 482 & 14.9 & 474 & 14.6 & 80.8 & 79.4 to 82.2 & 91 & 2.8 & 99 & 3.1 & 79.5 & 78.1 to 80.9 & $0.77(\mathrm{SA})$ \\
\hline \multicolumn{14}{|l|}{ Hypertensive disorders } \\
\hline $\begin{array}{l}\text { Moderate or severe } \\
\text { pre-eclampsia }\end{array}$ & 96 & 3.0 & 106 & 3.3 & 70.8 & 69.2 to 72.4 & 31 & 1.0 & 21 & 0.6 & 78.1 & 76.7 to 79.5 & $0.73(\mathrm{SA})$ \\
\hline Eclampsia & 2 & 0.1 & 8 & 0.2 & 12.5 & 11.4 to 13.6 & 7 & 0.2 & 1 & 0.0 & 50.0 & 48.3 to 51.7 & $0.20(\mathrm{SIA})$ \\
\hline $\begin{array}{l}\text { Premature labour* } \\
(\mathrm{O} 60.0)\end{array}$ & 141 & 4.3 & 87 & 2.7 & 57.5 & 55.8 to 59.2 & 37 & 1.1 & 91 & 2.8 & 35.5 & 33.9 to 37.1 & $0.42(\mathrm{MA})$ \\
\hline Placental abruption & 41 & 1.3 & 40 & 1.2 & 75 & 73.5 to 76.5 & 10 & 0.3 & 11 & 0.3 & 73.2 & 71.7 to 74.7 & $0.74(\mathrm{SA})$ \\
\hline
\end{tabular}

*Missing data $\leq 10$.

†Codes O60.0, O60.2 and O47.0.

FN, false negative; FP, false positive; MA, moderate agreement; PPV, positive predictive value; SA, substantial agreement; SIA, slight agreement.

hospitalisation and/or on hospitalisation within 2 years prior to the delivery, but without improvement.

Combining the two forms of pre-existing diabetes, the algorithm which mixed the codes $\mathrm{O} 24.0$ or O24.1 in the discharge abstract of delivery stay presented a PPV of $65.9 \%$ and a sensitivity of $75.7 \%$ (kappa index $=0.69$, substantial agreement).

\section{High blood pressure}

Previous high blood pressure was explored with the $\mathrm{O} 10$ diagnosis code. The PPV was $32.4 \%$ and the sensitivity was $37.9 \%$, with a fair agreement regarding the kappa index $(\mathrm{k}=0.34)$.

\section{Pregnancy-related disorders}

The concordance rate of gestational age at delivery was $91.8 \%$ (90.9 to 92.7). However, the gestational age was specified in weeks and days of gestation in medical records, while it was specified in weeks of gestation in the hospital data. Rounding up or down to the nearest whole number of weeks of gestation, the concordance rate increased to $98.3 \%$.

The pregnancy-related disorders are presented in table 2.

\section{Gestational diabetes}

Regarding gestational diabetes (O24.4 and O24.9 codes in the discharge abstract of delivery stay), the PPV was $80.8 \%$ (79.4 to 82.2 ) and the sensitivity was $79.5 \%$ (78.1 to 80.9). The association of these two codes (in comparison with only code O24.4) did not modify the number of false positives but decreased the number of false negatives. The algorithms that included the discharge abstracts from pregnancy hospitalisations decreased the PPV and increased the sensitivity. The kappa index for gestational diabetes was almost 0.80 ( $\mathrm{k}=0.76$, substantial agreement).

\section{Hypertensive disorders}

There were 213 cases of hypertensive disorders in the medical records and 239 in the discharge abstracts from the delivery stays (codes O10-O16). The PPV was 69.5\% (67.9 to 71.1 ) and the sensitivity was $77.9 \%$ (76.5 to 79.3 ). When we added the same codes but that were recorded during pregnancy or the $\mathrm{P} 000$ code which is recorded in the discharge abstract from a newborn stay, the results were similar. A kappa index of 0.71 indicates a substantial agreement between the two data sources.

Moderate or severe pre-eclampsia was identified in 106 cases in the hospital data (code O14 in the discharge abstracts for delivery stays), while 96 cases were recorded in the medical records; the PPV was $70.8 \%$ (69.2 to 72.4) and the sensitivity was $78.1 \%$ (76.7 to 79.5) (kappa index $=0.73$, substantial agreement). Eclampsia is a major and rare event. Nevertheless, we observed many false positives: two cases were recorded in the medical records and eight cases in the hospital data. Thus, the PPV was $12.5 \%$ and the sensitivity was $50.0 \%$, with a slight agreement regarding the kappa index $(\mathrm{k}=0.20)$.

\section{Premature labour, premature delivery}

Premature labour is the motive for a large number of hospitalisations in France. According to the guidelines from the national agency for the management of hospitalisation data (Agence Technique de l'Information Hospitalière (ATIH)), the O60.0 code corresponds to a premature labour. For this code, recorded in discharge abstracts of hospital stays during pregnancy, the PPV was 
$57.5 \%$ (55.8 to 59.2$)$ and the sensitivity was $35.5 \%$ (33.9 to 37.1). Adding other codes (eg, O60.0, O60.2 or O47.0, 'false labor before 37 completed weeks of gestation'), the PPV decreased $(32.5 \%)$ and the sensitivity increased $(75.2 \%)$. The kappa index for premature labour depending on the algorithm used was, respectively, 0.42 and 0.51 (moderate agreement).

Regarding premature deliveries with or without spontaneous labour (codes O60.1 and O60.3), the PPV was $85.8 \%$ and the sensitivity was $58.3 \%$ (kappa index $=0.66$, substantial agreement).

\section{Premature rupture of membranes}

Regarding the codes for PROM (O42) or the code for delayed delivery after spontaneous or unspecified rupture of membranes (O75.6) during the delivery stay, the PPV was $54.9 \%$ (53.2 to 56.6 ) and the sensitivity was $57.0 \%$ (55.3 to 58.7). When we added to the $\mathrm{O} 42$ code the $\mathrm{P} 011$ code from the newborn discharge abstract, the PPV was $56.2 \%$ (54.5 to 57.9 ) and the sensitivity was $60.0 \%$ (58.3 to 61.7$)$. The kappa index was around 0.50 for both algorithms, indicating a moderate agreement between the two data sources.

For placental abruption (code O45), the PPV was 75\% (73.5 to 76.5 ) and the sensitivity was $73.2 \%$ (71.7 to 74.7 ) (kappa index $=0.74$, substantial agreement).

\section{Delivery}

The results of delivery algorithms are presented in table 3 . The data for delivery in singleton or twin pregnancies presented, respectively, PPV of $98.3 \%$ (97.9 to 98.7) and $94.3 \%$ (93.4 to 95.1 ), sensitivity of $99.7 \%$ and $95.2 \%$, and kappa index of 0.64 (substantial agreement) and 0.95 (almost perfect agreement).

Regardless of the algorithm explored, the PPV for vaginal delivery was over $99 \%$. However, the sensitivity increased to $99.6 \%$ when we used the algorithm that included diagnosis codes and/or the corresponding codes for delivery procedures. For instrumental deliveries, the PPV decreased by $2 \%(88.2 \%$ (87.1 to 89.3$)$ ) and the sensitivity increased to $95.9 \%$ when the algorithm included diagnosis codes and/or procedure codes.

As regards caesarean births, the algorithm that included diagnosis codes and/or procedure codes improved the PPV to $98.5 \%$ and the sensitivity to $99.5 \%$. The PPV for emergency caesarean sections or planned caesarean sections (diagnosis and procedure codes) was, respectively, $83.0 \%$ and $80.4 \%$, and their sensitivity was $95.1 \%$ and $84.5 \%$.

For all delivery types, almost perfect agreement was obtained with the kappa index.

The PPV for episiotomy, which was calculated by comparing medical records and the procedure codes, was $90.1 \%$ (88.9 to 91.3 ) and the sensitivity was $86.0 \%$ (84.6 to 87.4) (kappa index $=0.86$, almost perfect agreement). The PPV for perineal tears was $86.2 \%$ (84.8 to 87.6 ) and the sensitivity was $76.4 \%$ (74.7 to 78.1 ) (kappa index=0.65, substantial agreement).
For the diagnosis codes corresponding to immediate PPH (O72.0 or O72.1), the PPV was $77.7 \%$ (76.3 to 79.1 ) and the sensitivity was $75.5 \%$ (74.0 to 77.0) (kappa index $=0.74$, substantial agreement). We explored an algorithm that included these codes and the procedure codes for manual removal of the placenta. In these cases, the PPV was $80.7 \%$ and the sensitivity was $13.1 \%$, with a fair agreement regarding the kappa index $(\mathrm{k}=0.21)$.

In order to select severe PPH, we explored advanced interventional procedures which indicated a second-line therapy (arterial embolisation, uterine or hypogastric artery ligation, haemostasis hysterectomy). First, when we included the relevant codes of advanced interventional procedures on immediate postpartum, the PPV was $67.8 \%$ and the sensitivity was $80.8 \%$. We then explored the performance of an algorithm that included the following:

- Relevant codes for advanced interventional procedures during the immediate postpartum period.

- Diagnosis codes corresponding to immediate PPH associated with general codes for advanced interventional procedures.

The PPV was $68.4 \%$ (66.8 to 70.0 ) and the sensitivity was $90.0 \%$ (89.0 to 91.0 ).

For both algorithms, we found a substantial agreement with the kappa index ( $\mathrm{k}=0.73$ and $\mathrm{k}=0.77$, respectively).

\section{Fetal mortality}

The results of fetal mortality algorithms are presented in table 3. As regards medically indicated abortion, we wanted to explore the algorithms proposed by the national agency ATIH for hospitalisation. First, we explored medical abortion from one delivery procedure code and a gestational age greater than or equal to 22 weeks of gestation (WG) and one of the codes specifying stillbirth (Z37.11, Z37.31, Z37.41, Z37.61, Z37.71). The PPV and the sensitivity were $91.5 \%$ (90.5 to 92.5) (kappa index $=0.91$, almost perfect agreement). The other algorithms (only newborn discharge abstract, or the association of maternal and newborn discharge abstracts) were not more powerful.

Regarding medical abortion linked to a fetal condition, the same algorithm was used, but the diagnosis code O35 (as the primary diagnosis) was added. The PPV was equal to $88.9 \%$ ( 87.8 to 90.0$)$ and the sensitivity was equal to $75.9 \%$ (74.4 to 77.4) (kappa index=0.81, almost perfect agreement).

According to the ATIH algorithm, among the codes specifying stillbirth (Z37.1, Z37.3, Z37.4, Z37.6, Z37.7 or O36.4 or O31.2), stillbirth presented a PPV of $89.4 \%$ (88.3 to 90.5 ) and a sensitivity of $95.4 \%$ (94.7 to 96.1 ) (kappa index $=0.92$, almost perfect agreement).

When the P95 code was added, the sensitivity increased to $99.2 \%$ but the PPV dropped to $60.6 \%$, with a substantial agreement for the kappa index nonetheless $(\mathrm{k}=0.73)$.

The concordance rate between vital status and the diagnosis codes for medical abortion from newborn discharge abstracts was $98.6 \%$ (98.2 to 99.0) for singleton 


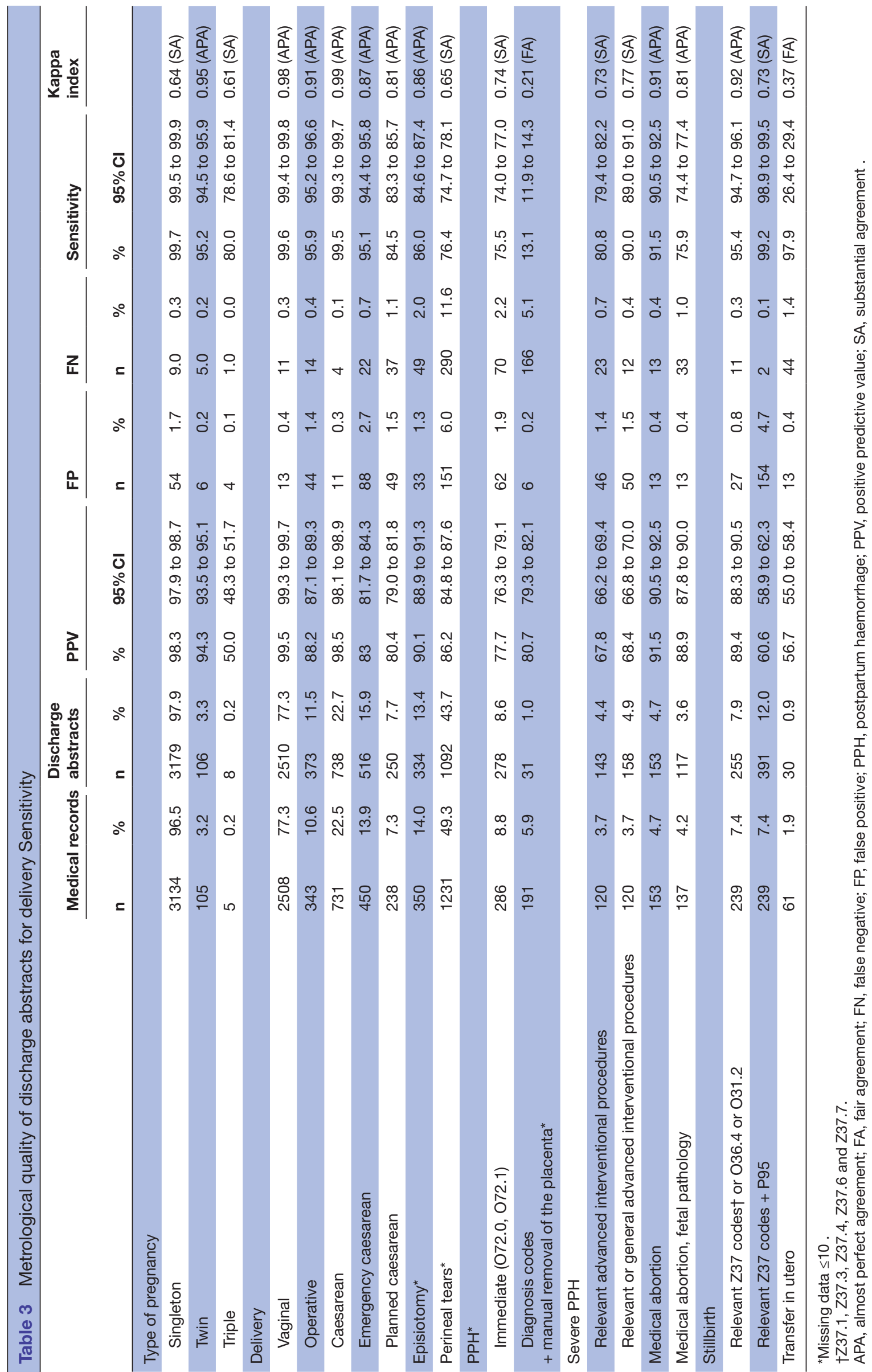


pregnancy. In case of multiple pregnancies, the rate was $100 \%$ for all children.

The concordance rate between vital status and the diagnosis codes for stillbirth from newborn discharge abstracts was $95.4 \%$ (94.7 to 96.1) for singleton pregnancy. For multiple pregnancies, the rate was $99.7 \%$ for the first-born or the second-born child, and $100 \%$ for the third-born child.

\section{Newborn indicators}

The concordance rate of newborn weight was $91.3 \%$ (90.3 to 92.3) in singleton pregnancy. The rate was $79.1 \%$ (70.5 to 87.7) for first-born and second-born in cases of multiple pregnancy. The concordance using Deming regression is presented in figure 1 . As regards the firstborn child, the median gap between the newborn weight mentioned in the medical record and the weight specified in the discharge abstract was $100 \mathrm{~g}$. The same gap was estimated for the first-born or second-born child in case of multiple pregnancies.

\section{Transfer in utero}

Sixty-one cases of in utero transfer were identified in the medical records, while only 30 cases were identified in the discharge abstracts. The PPV was $56.7 \%$ and the sensitivity was $27.9 \%$, with a fair agreement for the kappa index $(\mathrm{k}=0.37)$.

\section{DISCUSSION}

\section{Main findings}

To our knowledge, this is the first time a national validation study has been done for perinatal algorithms from the French national hospital database. The frequency of data observed in discharge abstracts was sometimes very close to those observed in medical records, particularly for maternal characteristics, pregnancy characteristics (parity, type of pregnancy, type of delivery, stillbirth, termination of pregnancy for medical reasons) and child birth weight. However, we found the algorithms for pregnancy disorders to be insufficient.

The results of our study may allow researchers to target the best performing algorithms. For example, the best case-finding algorithm of premature deliveries presented substantial agreement, while the concordance rate of gestational age at delivery was almost perfect. It appears that gestational age associated with the onset of delivery should be taken into account when exploring prematurity.

It is very important to adjust the design of a study to the quality of the available data. The case-finding algorithms which present lower PPV and/or sensitivity can be used for descriptive purposes if the total number of women is close to what is expected. Regarding premature labour, the concordance between the hospital database and medical records was poor according to the diagnosis code required by the technical agency for information on hospital care (ATIH) that managed the hospital data (O60.0). We explored other diagnosis codes recorded at the end of the hospitalisation for delivery or at the end of at least one hospitalisation during the pregnancy, which improved concordance slightly. This result may be explained by several factors: there is no consensus on the clinical definition, and the definition of diagnosis codes is subject to interpretation. However, the best performing algorithm estimated the prevalence of premature labour to 5.4\%. In France, a national perinatal survey is conducted at regular intervals on a representative sample of births. In 2016, this survey estimated that hospitalisation for premature labour occurred in $5.4 \%$ of women. These results were close to those of the national perinatal survey conducted in 2010. ${ }^{9}$ However, our sample design could significantly increase this rate.

For longitudinal epidemiological studies, caution is required in case of very low sensitivity and/or PPV. For these studies, it is better to use case-finding algorithms that provide substantial or perfect agreement. In a pilot study from 2012 based on 20 cases of gestational diabetes from 300 medical records, our team found a PPV of $88.9 \%(74.3-100)$ and a sensitivity of $72.7 \%$ (54.1-91.3). The current study found similar results despite a slight improvement in sensitivity. Unfortunately, we are not able to compare the frequency of gestational diabetes with other studies in France because of the artificially increased prevalence in our sample $(14.5 \%$ in our study vs $10.8 \%$ in the 2016 national perinatal survey). The use of a complementary French database for ambulatory care (reimbursement of treatment, biological testing and medical devices) could improve the identification of women with GDM, but the metrological quality of this algorithm has not yet been assessed. In case of stillbirth or termination of pregnancy for medical reasons, it seems possible to study these two indicators not only for descriptive studies, but also for longitudinal studies. Similar to what is already done for maternal mortality, ${ }^{30}$ the French hospital database could monitor these two additional indicators.

On the contrary, it would be unwise in the current situation to use the French hospital database to undertake longitudinal studies on certain pregnancy disorders because of their low PPV and sensitivity. Several factors may explain low predictive value or sensitivity seen in these disorders. First, the original and main objective of this standardised database is hospital financing, and a number of procedure or diagnosis codes are not allocated to medical fees. Certain diagnoses that are not financially valuated may remain uncoded.

Furthermore, we explored the identification of severe $\mathrm{PPH}$ via obstetrical procedures. One of the two procedures studied (uterine check post natural placental delivery) concerns only a very small proportion of this type of procedures. In most cases, placental delivery occurs after intravenous oxytocin injection $(84 \%)$, so the placental delivery can no longer considered natural. ${ }^{9}$ The procedure code no longer corresponds to clinical reality in these cases, and improvements are needed in terms of information quality. 


\section{Strengths and limitations}

We conducted a validation study comparing individual data from the hospital discharge abstract with medical records. Some limitations have to be acknowledged. The data collection was performed by a perfectly trained clinical research associate but not by a medical specialist, such as an obstetrician or a midwife. In addition, the maternity units included in our study were not distributed equally throughout the French territory. The results of our study investigated national data and are therefore useful for studies carried out on a national scale, but regional or local studies would need a local evaluation as a result of interhospital variability.

Our study also has some strengths. First, in France almost all deliveries occur in a hospital. Second, we explored a large number of perinatal indicators, whereas many studies focus on a single condition. ${ }^{22}$ 31-33 Overall, 70 items were collected for each hospital stay by a single clinical research associate. Third, despite the challenges of recruiting centres that would have to dedicate considerable time to the study, our national study included maternity units of all types and with all volumes of deliveries. Finally, we explored more than 3200 pairs of medical records-discharge abstracts.

\section{CONCLUSION}

This first national validation study of a large set of perinatal algorithms provides valuable information for researchers about the quality of the French national hospital database. For certain case-finding algorithms, our results suggested that this database may be an appropriate data source for epidemiological studies. For others (with low PPV/sensitivity), we would discourage longitudinal studies. In recent years, a professionalisation of the staff in charge of health information coding may be an important lever for improving the quality of information. Moreover, the joint association of the French hospital database and 'National System of Health Data' (SNDS - Système National des Données de Santê)database, which collects individual non-hospital healthcare data, may improve case identification of some conditions that impact the course of pregnancy.

Acknowledgements We would like to warmly thank all participating hospitals: Armentières, Bar-le-Duc, Bayonne, Dole, Falaise, Le Creusot, Montélimar, Pau, Privas, Quimper, Saint-Lô and Valenciennes (hospitals), and Avignon, Brest, Caen, Dijon, Grenoble, Lille, Montpellier, Nancy, Saint-Etienne and Strasbourg (university hospitals). We would like to thank S Belhadj for data collection and S Rankin for her thorough proof-reading of this article.

Contributors KG conceptualised and designed the study, coordinated the inclusion of hospitals and the data collection, interpreted the data, and wrote the paper. $\mathrm{JC}$ contributed to the conception of the study, performed the statistical analyses and reviewed the paper. EB contributed to the conception of the study and ran a software program to select the discharge abstracts and corresponding medical records. PT-B conceptualised and designed the study, and contributed to the analysis strategy and the interpretation of the results. CQ conceptualised and designed the study, oversaw the data analysis and interpretation, and critically reviewed and revised the manuscript drafts. The corresponding author attests that all listed authors meet the authorship criteria. All authors take responsibility for the integrity of the data and the accuracy of the data analysis.
Funding This work was supported by the National Research Agency (grant number: ANR-15-CE36-0006-01), the Medical Research Foundation (FRM) and the Direction de la Recherche, des Etudes, de l'Evaluation et des Statistiques.

Competing interests None declared.

Patient consent for publication Not required.

Ethics approval This study was approved by the French National Committee for Data Protection (registration number 9132091). To meet the requirement of the data protection agency, the family names and first names were removed, the date of birth was replaced by the age at delivery, and the dates of admission and discharge were replaced by the length of stay.

Provenance and peer review Not commissioned; externally peer reviewed.

Data availability statement All data relevant to the study are included in the article or uploaded as supplementary information. The use of these data by our department was approved by the National Committee for Data Protection. We are not allowed to transmit these data (DR-2015-201).

Open access This is an open access article distributed in accordance with the Creative Commons Attribution Non Commercial (CC BY-NC 4.0) license, which permits others to distribute, remix, adapt, build upon this work non-commercially, and license their derivative works on different terms, provided the original work is properly cited, appropriate credit is given, any changes made indicated, and the use is non-commercial. See: http://creativecommons.org/licenses/by-nc/4.0/.

ORCID iD

Catherine Quantin http://orcid.org/0000-0001-5134-9411

\section{REFERENCES}

1 Quantin C, Benzenine E, Fassa M, et al. Evaluation of the interest of using discharge Abstract databases to estimate breast cancer incidence in two French departments. Stat J IAOS 2012;28:73-85.

2 Remontet L, Mitton N, Couris CM, et al. Is it possible to estimate the incidence of breast cancer from medico-administrative databases? Eur J Epidemiol 2008;23:681-8.

3 Quantin C, Benzenine E, Hägi M, et al. Estimation of national colorectal-cancer incidence using claims databases. J Cancer Epidemiol 2012;2012:1-7.

4 Abdulmalak C, Cottenet J, Beltramo G, et al. Haemoptysis in adults: a 5-year study using the French nationwide Hospital administrative database. Eur Respir J 2015;46:503-11.

5 Couris CM, Polazzi S, Olive F, et al. Breast cancer incidence using administrative data: correction with sensitivity and specificity. J Clin Epidemiol 2009;62:660-6.

6 Lorgis L, Cottenet J, Molins G, et al. Outcomes after acute myocardial infarction in HIV-infected patients: analysis of data from a French nationwide hospital medical information database. Circulation 2013;127:1767-74.

7 Quantin C, Cottenet J, Vuagnat A, et al. [Quality of perinatal statistics from hospital discharge data: comparison with civil registration and the 2010 National Perinatal Survey]. J Gynecol Obstet Biol Reprod 2014;43:680-90.

8 Blondel B, Lelong N, Kermarrec M, et al. [Trends in perinatal health in France between 1995 and 2010: Results from the National Perinatal Surveys]. J Gynecol Obstet Biol Reprod 2012;41:151-66.

9 Blondel B, Coulm B, Bonnet C, et al. Trends in perinatal health in metropolitan France from 1995 to 2016: results from the French national perinatal surveys. J Gynecol Obstet Hum Reprod 2017;46:701-13.

10 Garrison LP, Neumann PJ, Erickson P, et al. Using real-world data for coverage and payment decisions: the ISPOR real-world data Task force report. Value Health 2007;10:326-35.

11 James S, Rao SV, Granger CB. Registry-based randomized clinical trials--a new clinical trial paradigm. Nat Rev Cardiol 2015;12:312-6.

12 Bossuyt PM, Reitsma JB, Bruns DE, et al. Towards complete and accurate reporting of studies of diagnostic accuracy: the STARD initiative. BMJ 2003;326:41-4.

13 Benchimol El, Manuel DG, To T, et al. Development and use of reporting guidelines for assessing the quality of validation studies of health administrative data. J Clin Epidemiol 2011;64:821-9.

14 De Coster C, Quan H, Finlayson A, et al. Identifying priorities in methodological research using ICD-9-CM and ICD-10 administrative data: report from an international Consortium. BMC Health Serv Res 2006;6:77.

15 Gini R. A Validation Odyssey: from big data to local intelligence. [Internet]. Rotterdam: Erasmus University, 2016. https://www. 
researchgate.net/profile/Rosa_Gini/publication/309428868 A_Validation_Odyss ey_From_big_data_to_local_intelligence/ links/5810884a08aea04bbcbd03bd/A-Validation- Odyssey-Frombig-data-to-local-intelligence.pdf

16 Amed S, Vanderloo SE, Metzger D, et al. Validation of diabetes case definitions using administrative claims data. Diabet Med 2011;28:424-7.

17 Guttmann A, Nakhla M, Henderson M, et al. Validation of a health administrative data algorithm for assessing the epidemiology of diabetes in Canadian children. Pediatr Diabetes 2010;11:122-8.

18 Sagot P, Mourtialon P, Benzenine E, et al. Accuracy of blood transfusion in postpartum hemorrhage to assess maternal morbidity. Eur J Obstet Gynecol Reprod Biol 2012;162:160-4.

19 Chantry AA, Deneux-Tharaux C, Bal G, et al. [French hospital discharge database: data production, validity, and origins of errors in the field of severe maternal morbidity]. Rev Epidemiol Sante Publique 2012;60:177-88.

20 Aboa-Eboulé C, Mengue D, Benzenine E, et al. How accurate is the reporting of stroke in hospital discharge data? A pilot validation study using a population-based stroke Registry as control. J Neurol 2013;260:605-13.

21 Hanf M, Quantin C, Farrington P, et al. Validation of the French National health insurance information system as a tool in vaccine safety assessment: application to febrile convulsions after pediatric measles/mumps/rubella immunization. Vaccine. 2013;31:5856-62. 2 déc.

22 Fermaut M, Fauconnier A, Brossard A, et al. Detection of complicated ectopic pregnancies in the hospital discharge database: a validation study. PLoS One 2019;14:e0217674.
23 p B-levy, Duret S, Gilleron V, et al. Étude de validation des codes diagnostics de l'insuffisance cardiaque. Rev epidemiol sante 2018;66:S199-200.

24 Bujang MA, Adnan TH. Requirements for minimum sample size for sensitivity and specificity analysis. J Clin Diagn Res 2016;10:YE01YE06.

25 Linnet K. Estimation of the linear relationship between the measurements of two methods with proportional errors. Stat Med 1990;9:1463-73.

26 Linnet K. Evaluation of regression procedures for methods comparison studies. Clin Chem 1993;39:424-32.

27 Fuhrman C, Chouaïd C. [Concordance between two variables: numerical approaches (qualitative observations - the kappa coefficient-; quantitative measures]. Rev Mal Respir 2004;21:123-5.

28 Viera AJ, Garrett JM. Understanding interobserver agreement: the kappa statistic. Fam Med 2005;37:360-3.

29 Landis JR, Koch GG. The measurement of observer agreement for categorical data. Biometrics 1977;33:159-74.

30 Saucedo M, Denaux-Tharaud C. Évaluation de la fiabilité du PMSI pour l'identification des morts maternelles intra hospitalières en France. Rev epidemiol sante 2019.

31 Flood M, Pollock W, McDonald SJ, et al. Accuracy of postpartum haemorrhage data in the 2011 Victorian perinatal data collection: results of a validation study. Aust N Z J Obstet Gynaecol 2018;58:210-6.

32 Bowker SL, Savu A, Lam NK, et al. Validation of administrative data case definitions for gestational diabetes mellitus. Diabetic Medicine 2017;34:51-5.

33 Korst LM, Gregory KD, Gornbein JA. Elective primary caesarean delivery: accuracy of administrative data. Paediatr Perinat Epidemiol 2004;18:112-9. 